\title{
Residual flexural property of water absorbed CFRP during thermal cycling
}

\author{
H. Katogi, K. Takemura \& N. Iijima \\ Department of Mechanical Engineering, Kanagawa University, Japan
}

\begin{abstract}
This study investigated the effect of water absorption on the residual flexural property of CFRP during thermal cycling. Water absorption tests of CFRP and epoxy resin were conducted for 3 hours and 100 hours at $90^{\circ} \mathrm{C}$. Thermal cycling tests of water absorbed CFRP and epoxy resin were also conducted. The temperature of the thermal cycling test ranged from $-196^{\circ} \mathrm{C}$ to room temperature, and the maximum number of cycles was $10^{3}$ cycles. A static three-point flexural test of water absorbed CFRP was conducted after the thermal cycling test. A damage observation of CFRP during thermal cycling was performed. A singleedge notched bending test of water absorbed epoxy resin was also conducted. As a result, the following conclusions were obtained. In the case where the water absorption rate was $0.3 \%$ ( 3 hours), the flexural strength and modulus of CFRP decreased with an increase in the number of cycles. In the case where the water absorption rate was $1.1 \%$ (100 hours), there was almost no change in the flexural strength and modulus of CFRP. From the damage observation, crack initiations in the cross section of $0.3 \%$ and $1.1 \%$ water absorbed CFRP were found during thermal cycling. The number of cracks in the cross section of $0.3 \%$ and $1.1 \%$ water absorbed CFRP increased with an increase in the number of cycles. The Mode I fracture toughness of $2.6 \%$ (100 hours) water absorbed epoxy resin increased compared with that of $0.7 \%$ ( 3 hours) water absorbed epoxy resin during thermal cycling. Therefore, the flexural property of CFRP was affected by the Mode I fracture toughness of water absorbed epoxy resin.

Keywords: CFRP, residual flexural property, thermal cycling, crack, water absorption, mode I fracture toughness.
\end{abstract}




\section{Introduction}

Carbon Fiber Reinforced Plastic (CFRP), which has a high level of specific stiffness and strength, is focused on as a structural material for reusable launch vehicles, which will be used under water and in thermal cycling environments. Therefore, the effects of water absorption [1-7] and thermal cycling [8-10] on the mechanical properties of CFRP have been studied.

Katogi et al [5] reported on the flexural property of CFRP in a hot-wet environment. The flexural strength and modulus of the CFRP decreased with an increase in immersion time because blisters occurred in CFRP in a hot-wet environment over the long term. Research into Mode I interlaminar fracture toughness of CFRP following freezing after water immersion has also been published [11]. The flexural property and Mode I interlaminar fracture toughness of CFRP after water absorption and freezing decreased with an increase in immersion time. Katoh et al. [8] reported on the compressive strength of CFRP during thermal cycling, which decreased with an increase in the number of cycles because of the initiation of cracks in CFRP during thermal cycling. The mechanical properties of water absorbed CFRP during thermal cycling should be investigated in respect of its application as a structural material in reusable launch vehicles. However, there are few papers about the mechanical properties of water absorbed CFRP during thermal cycling.

This study investigated the residual flexural property of water absorbed CFRP during thermal cycling.

\section{Specimens}

For the fabrication of CFRP, plain woven carbon fiber (Torayca cloth CO6343, Toray Co., Ltd.) was used as reinforcement, and epoxy resin (jER 828, Mitsubishi Chemical Co., Ltd.) was used as matrix. Hand lay-up was employed as the molding method. As regards molding conditions, the pressure was $2 \mathrm{MPa}$, the temperature was $90^{\circ} \mathrm{C}$, while molding time was three hours. The fiber volume fraction of CFRP was 55\%. The CFRP for the static three-point flexural test was fabricated based on Japanese Industrial Standard (JIS) K7074. The specimen was $100 \mathrm{~mm}$ in length, $10 \mathrm{~mm}$ wide and $2 \mathrm{~mm}$ thick.

Epoxy resin plate (jER 828, Mitsubishi Chemical Co., Ltd.) was fabricated, using the resin casting method. The molding time was three hours at a molding temperature of $90^{\circ} \mathrm{C}$.

The epoxy resin specimen for the flexural test was fabricated based on JIS K 7171. Its measurements were as follows: length $80 \mathrm{~mm}$, width $10 \mathrm{~mm}$ and thickness $4 \mathrm{~mm}$.

Fabrication of the specimen of epoxy resin for the Single Edge Notched Beam (SENB) test was based on the American Society for Testing and Materials (ASTM) D 5045-93. The specimen was $44 \mathrm{~mm}$ long, $8 \mathrm{~mm}$ wide and $4 \mathrm{~mm}$ thick. The initial crack length was $4 \mathrm{~mm}$.

CFRP and epoxy resin specimens were immersed in distilled water for 3 hours and 100 hours at $90^{\circ} \mathrm{C}$. Water absorption rates of the CFRPs immersed for 
3 hours and 100 hours were $0.3 \%$ and $1.1 \%$, respectively. Water absorption rates of the epoxy resins immersed for 3 hours and 100 hours were $0.7 \%$ and $2.6 \%$, respectively.

\section{Testing methods}

\subsection{Thermal cycling test}

Thermal cycling tests of water absorbed CFRP and epoxy resin were conducted. The temperature of the thermal cycling test ranged from $-196^{\circ} \mathrm{C}$ to room temperature (R.T.). The maximum number of cycles was $10^{3}$ cycles.

\subsection{Static three-point flexural test}

A three-point flexural test of water absorbed CFRP was conducted after the thermal cycling test based on JIS K 7074, and a three-point flexural test of water absorbed epoxy resin was conducted after the thermal cycling test based on JIS K 7171. The environmental temperature was R.T. and crosshead speeds of CFRP and epoxy resin were $5 \mathrm{~mm} / \mathrm{min}$ and $2 \mathrm{~mm} / \mathrm{min}$, respectively. The number of specimens was five.

\subsection{SENB test}

The SENB test of water absorbed epoxy resin following the thermal cycling test was conducted based on ASTM D 5045-93. Crosshead speed was $1 \mathrm{~mm} / \mathrm{min}$, environmental temperature was R.T. and the number of specimens was five. The maximum number of cycles was $10^{2}$ cycles.

\subsection{Damage observation}

The center of water absorbed CFRP was cut in a longitudinal direction. The cross section of water absorbed CFRP during thermal cycling was observed by means of an optical microscope (GX71, OLMPUS Co., Ltd.). The maximum number of cycles was $10^{3}$ cycles.

\section{Results and discussion}

\subsection{Flexural property of water absorbed epoxy resin during thermal cycling}

Figure 1 shows the flexural property of water absorbed epoxy resin during thermal cycling. In the case where the water absorption rate was $0.7 \%$, the flexural strength of water absorbed epoxy resins at 10 cycles and $10^{2}$ cycles decreased, compared with that of water absorbed epoxy resin at one cycle. The flexural strength of water absorbed epoxy resin at $10^{3}$ cycles rapidly decreased, compared with that of water absorbed epoxy resin at $10^{2}$ cycles. The flexural modulus of water absorbed epoxy resin decreased with an increase in the number of cycles. 


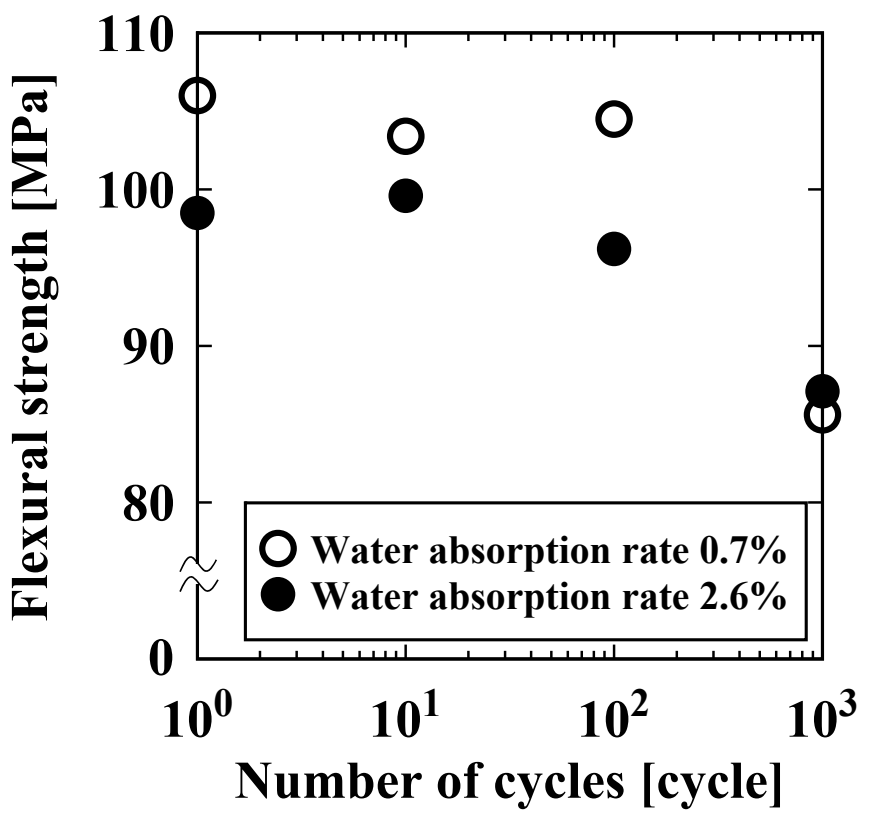

(a) Flexural strength.

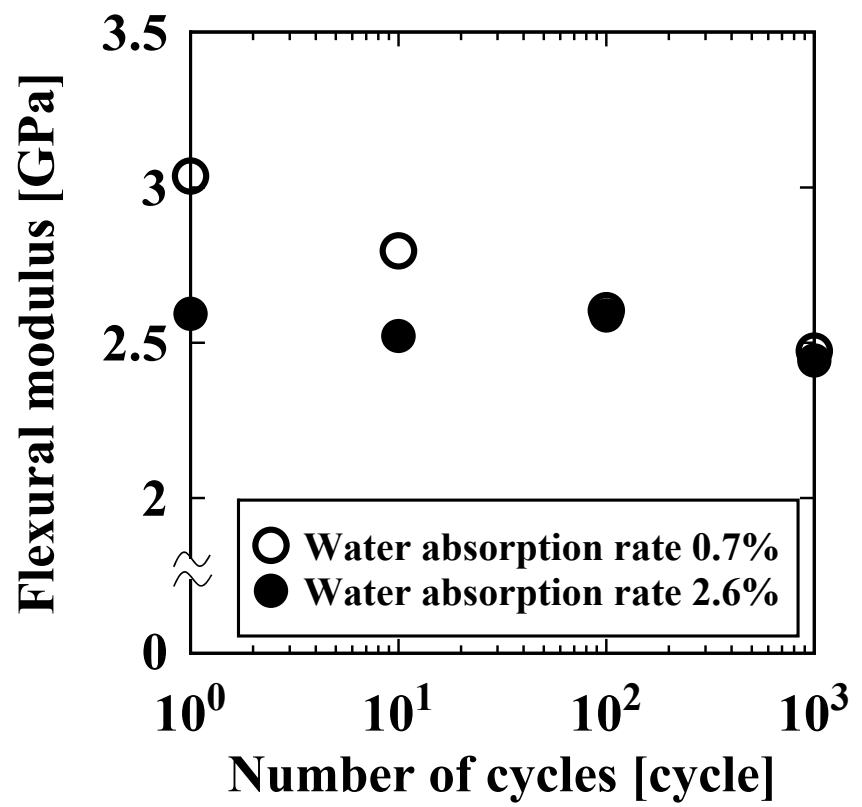

(b) Flexural modulus.

Figure 1: Flexural property of water absorbed epoxy resin during thermal cycling. 
In the case where the water absorption rate was $1.1 \%$, the flexural strength of water absorbed epoxy resin decreased with an increase in the number of cycles, except for the case of 10 cycles. In addition, the flexural strength of water absorbed epoxy resin at $10^{3}$ cycles rapidly deceased compared with that of water absorbed epoxy resin at $10^{2}$ cycles. There was almost no change in the flexural modulus of water absorbed epoxy resin with an increase in the number of cycles. So, the flexural property of epoxy resin during thermal cycling was affected by the water absorption rate.

Figure 2 shows water absorbed epoxy resin at $10^{3}$ cycles. In the case where water absorption rates were $0.7 \%$ and $2.6 \%$, the crack in the epoxy resin was initiated at $10^{3}$ cycles. So, crack initiation of the crack in water absorbed epoxy resin was affected by the expansion and contraction of penetrated water during thermal cycling.

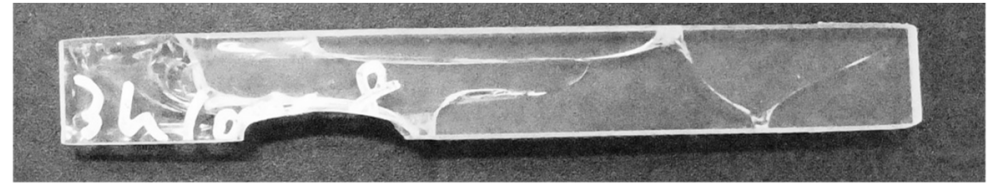

\section{$20 \mathrm{~mm}$}

(a) Water absorption rate $0.7 \%$.

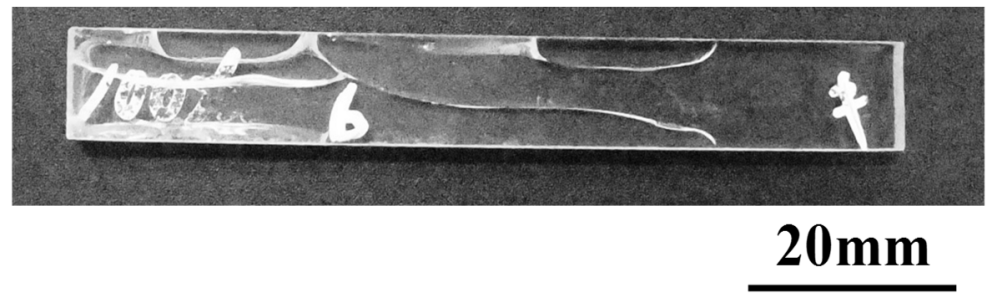

(b) Water absorption rate $2.6 \%$.

Figure 2: Water absorbed epoxy resin at $10^{3}$ cycles.

\subsection{Effect of thermal cycling on the Mode I fracture toughness of water absorbed epoxy resin}

Figure 3 shows the Mode I fracture toughness of water absorbed epoxy resin during thermal cycling. In the case in which the water absorption rate was $0.7 \%$, the Mode I fracture toughness of water absorbed epoxy resin decreased with an increase in the number of cycles. Where the water absorption rate was $2.6 \%$, there was almost no change in the Mode I fracture toughness of water absorbed epoxy resin. The Mode I fracture toughness of 2.6\% water absorbed epoxy resin increased compared with that of $0.7 \%$ water absorbed epoxy resin. The $2.6 \%$ water absorbed epoxy resin could be ductilized. Therefore, the Mode I fracture toughness of water absorbed epoxy resin during thermal cycling was affected by ductilization at a high water absorption rate. 


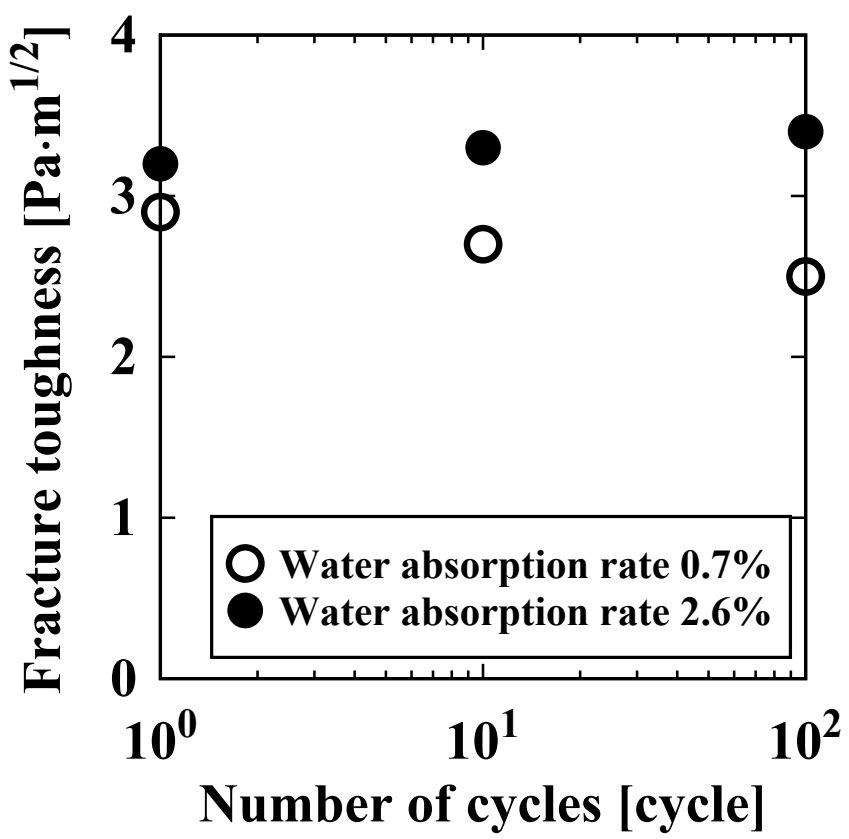

Figure 3: Mode I fracture toughness of water absorbed epoxy resin during thermal cycling.

\subsection{Flexural property of water absorbed CFRP during thermal cycling}

Figure 4 shows the flexural property of water absorbed CFRP during thermal cycling. The flexural strength and modulus of $0.3 \%$ water absorbed CFRP decreased with an increase in the number of cycles, but, with an increase in the number of cycles, there was almost no change in the flexural strength and modulus of $1.1 \%$ water absorbed CFRP. Therefore, the flexural property of CFRP was affected by an increase in the water absorption rate.

Figure 5 shows damage observation of a cross section of water absorbed CFRP during thermal cycling, while Table 1 displays the number of cracks in the cross section of water absorbed CFRP during thermal cycling. Where water absorption rates were $0.3 \%$ and $1.1 \%$, cracking was found in the cross section of water absorbed CFRP during thermal cycling. The number of cracks in the cross sectional areas of $0.3 \%$ and $1.1 \%$ water absorbed CFRP increased with an increase in the number of cycles. Furthermore, the number of cracks in the cross section of water absorbed CFRP at $10^{3}$ cycles rapidly increased compared with that of water absorbed CFRP at $10^{2}$ cycles. Crack initiation in CFRP was affected due to the matrix crack and debonding at interface between fiber and resin during thermal cycling. However, the Mode I fracture toughness of epoxy resin during thermal cycling was improved by an increase in water absorption rate. Therefore, the flexural property of CFRP during thermal cycling was affected by ductilization of the water absorbed matrix. 


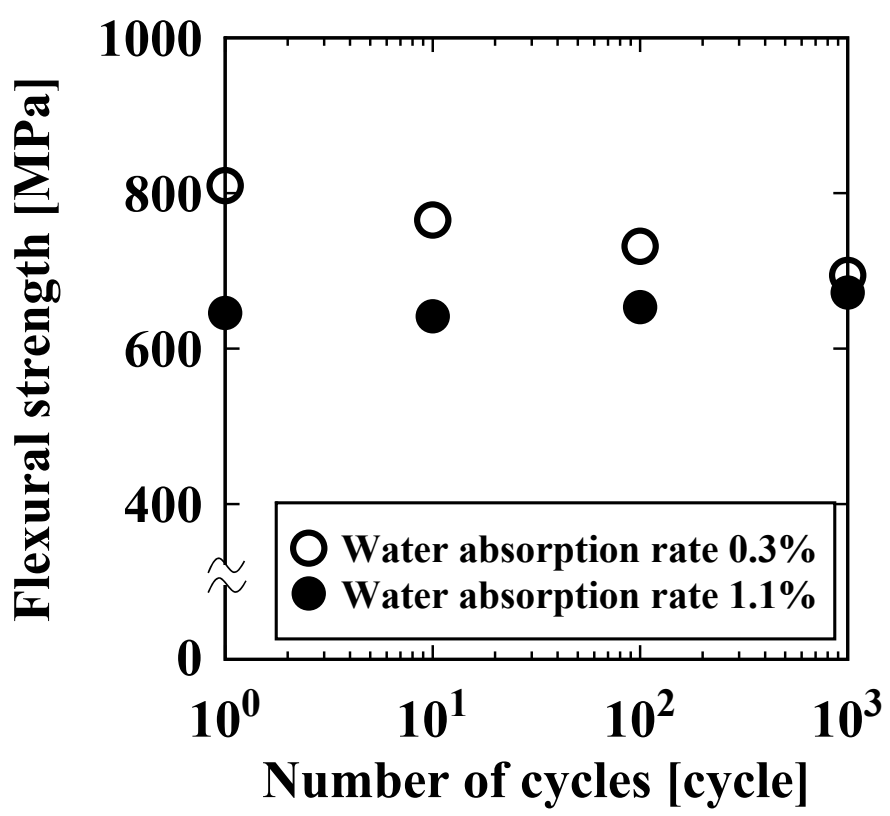

(a) Flexural strength.

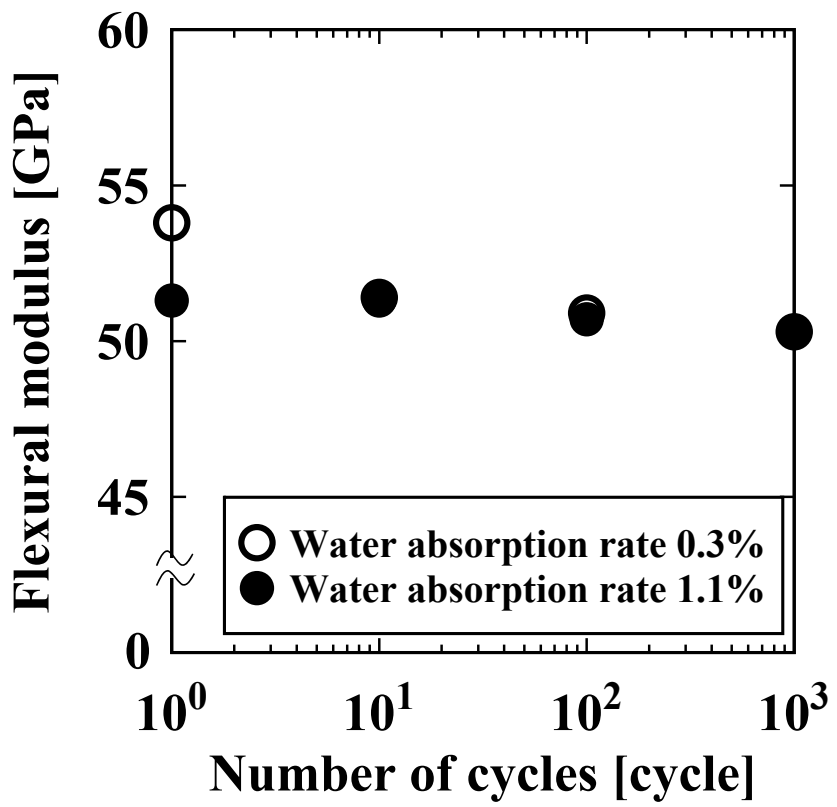

(b) Flexural modulus.

Figure 4: Flexural property of water absorbed CFRP during thermal cycling. 


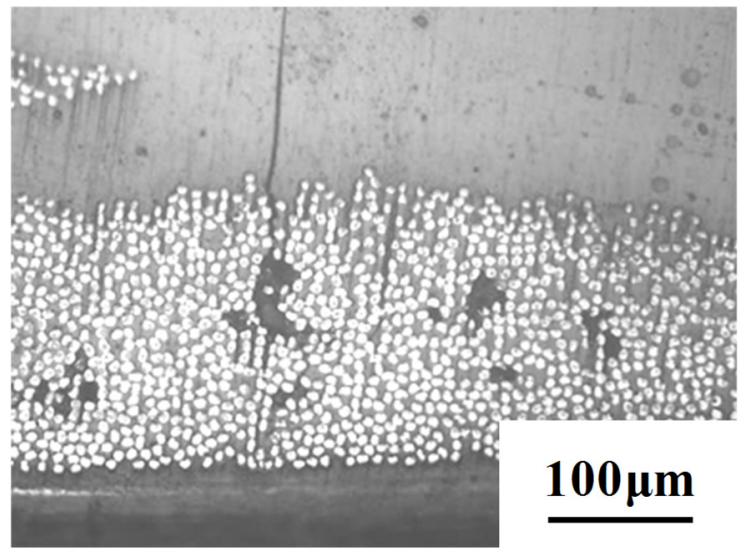

(a) Water absorption rate $0.3 \%$.

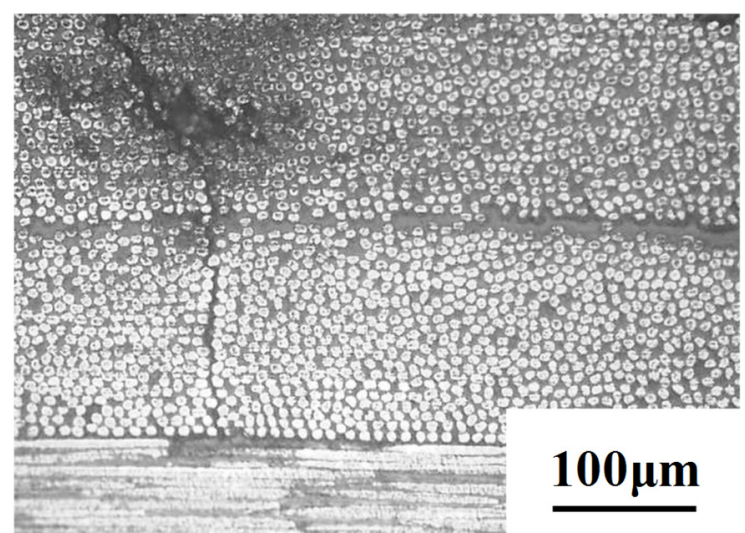

(b) Water absorption rate $1.1 \%$.

Figure 5: Damage observation of cross section of water absorbed CFRP during thermal cycling.

Table 1: $\quad$ Number of cracks of water absorbed CFRP during thermal cycling.

\begin{tabular}{|c|c|c|c|c|}
\hline & 1 cycle & 10 cycles & $10^{2}$ cycles & $10^{3}$ cycles \\
\hline Water absorption rate $0.3 \%$ & 3 & 5 & 9 & 35 \\
\hline Water absorption rate $1.1 \%$ & 1 & 4 & 6 & 30 \\
\hline
\end{tabular}

\section{Conclusions}

In this study, the residual tensile property of water absorbed CFRP during thermal cycling was investigated. As a result, the following conclusions are obtained. 
1. In the case that the water absorption rate was $0.7 \%$, the flexural strength of water absorbed epoxy resin decreased with an increase in the number of cycles, with the exception of $10^{2}$ cycles, and the flexural modulus of water absorbed epoxy resin decreased with an increase in the number of cycles. In the case where the water absorption rate was $2.6 \%$, the flexural strength of water absorbed epoxy resin decreased with an increase in the number of cycles, except for the case of 10 cycles. However, with an increase of number of cycles, there was almost no change in the flexural modulus of water absorbed epoxy resin. The Mode I fracture toughness of $2.6 \%$ water absorbed epoxy resin increased, compared with that of $0.7 \%$ water absorbed epoxy resin during thermal cycling. Therefore, the flexural property and Mode I fracture toughness of epoxy resin during thermal cycling was affected due to ductilization by the water absorption rate.

2. The flexural property of $0.3 \%$ water absorbed CFRP decreased with an increase in the number of cycles, but there was almost no change in the flexural property of $1.1 \%$ water absorbed CFRP with an increase on the number of cycles. Where water absorption rates were $0.3 \%$ and $1.1 \%$, the number of cracks in the cross section of water absorbed CFRP increased with an increase in the number of cycles. Therefore, the flexural property of CFRP during thermal cycling was affected by ductilization of the water absorbed matrix.

\section{References}

[1] Soutis, C., Modelling Open Hole Compressive Strength of Composite Laminates Tested in Hot Wet Condition, Plastics, Rubber and Composites, 38, pp. 55-60, 2009.

[2] Tanaka, K., Fukushima, Y., Kashihara, K. \& Katayama, T., Effect of Water Absorption on the Mechanical Properties of Continuous Carbon Fibre Reinforced Polycarbonate Composites, WIT Transactions on the Built Environment, 112, pp. 153-162, 2010.

[3] Murthy, H.N.N, Sreejith, M. \& Krishna, M., Seawater Durability of Epoxy/Vinyl Ester Reinforced with Glass/Carbon Composites, Journal of Reinforced Plastics and Composites, 29, pp. 1491-1499, 2012.

[4] Mouritz, A.P., Environmental Durability of Z-Pinned Carbon Fibre-Epoxy Laminate Exposed to Water, Composites Science and Technology, 72, pp. 1568-1574, 2012.

[5] Katogi, H., Takemura, K. \& Shimamura, Y., Mechanical Properties of Carbon Fiber Reinforced Plastics under Hot-Wet Environment, Key Engineering Materials, 462-463, pp. 207-212, 2012.

[6] Tanaka, K., Hanasaki, T. \& Katayama, T., Effect of Water Absorption on the Mechanical Properties of Carbon Fiber Reinforced Polycarbonate Composites, WIT Transactions on the Built Environment, 137, pp. 283-289, 2014. 
[7] Kafodya, I., Xian, G. \& Li, H., Durability Study of Pultruded CFRP Plates Immersed in Water and Seawater under Sustained Bending: Water Uptake and Effects on the Mechanical Properties, Composites Part B: Engineering, 70, pp. 138-148, 2015.

[8] Katoh, H., Shimokawa, T., Hamaguchi, Y., Mizuno, H., Nakamura, H. \& Asagumo, R., Microcracking and Compressive Strength Degradation of Carbon Fiber/Polyimide Resin Composites by Thermal Cycling, Journal of the Society of Materials Science, Japan, 53, pp. 1109-1116, 2004 (in Japanese).

[9] Eslami-Frasani, R., Khalili, S.M.R. \& Najafi, M., Effect of Thermal Cycling on Hardness and Impact Properties of Polymer Composites Reinforced by Basalt and Carbon Fibers, Journal of Thermal Stresses, 36, pp. 684-698, 2013.

[10] Tamiaki, M., Fujii T. \& Okubo, K., Leak Prevention of Nitrogen Gas for Plain Woven CF/Epoxy Composites by Filling Nanofiller under Cryothermal Fatigue, Journal of the Society of Materials Science, Japan, 64, pp. 739-744, 2015 (in Japanese).

[11] Katogi, H. \& Takemura, K., Flexural Property and Mode I Interlaminar Fracture Toughness of Plain Woven Carbon Fiber Reinforced Plastics after Water Absorption and Freezing, Key Engineering Materials, 627, pp. 109$112,2015$. 